\title{
Climatic and societal impacts of a volcanic double event at the dawn of the Middle Ages
}

\author{
Matthew Toohey ${ }^{1,2}$ (D) Kirstin Krüger ${ }^{3}$. \\ Michael Sigl $^{4,5} \cdot$ Frode Stordal $^{3,6} \cdot$ Henrik Svensen $^{6}$
}

\begin{abstract}
Volcanic activity in and around the year $536 \mathrm{CE}$ led to severe cold and famine, and has been speculatively linked to large-scale societal crises around the globe. Using a coupled aerosol-climate model, with eruption parameters constrained by recently re-dated ice core records and historical observations of the aerosol cloud, we reconstruct the radiative forcing resulting from a sequence of two major volcanic eruptions in 536 and $540 \mathrm{CE}$. We estimate that the decadal-scale Northern Hemisphere (NH) extra-tropical radiative forcing from this volcanic "double event" was larger than that of any period in existing reconstructions of the last 1200 years. Earth system model simulations including the volcanic forcing show peak $\mathrm{NH}$ mean temperature anomalies reaching more than $-2{ }^{\circ} \mathrm{C}$, and show agreement with the limited number of available maximum latewood density temperature reconstructions. The simulations also produce decadal-scale anomalies of Arctic sea ice. The simulated cooling is interpreted in terms of probable impacts on agricultural production in Europe, and implies a high likelihood of multiple years of significant decreases in crop production across Scandinavia, supporting the theory of a connection between the 536 and 540 eruptions and evidence of societal crisis dated to the mid-6th century.
\end{abstract}

Electronic supplementary material The online version of this article (doi:10.1007/s10584-016-1648-7) contains supplementary material, which is available to authorized users.

Matthew Toohey

mtoohey@geomar.de

1 Ocean Circulation and Climate Dynamics, GEOMAR Helmholtz Centre for Ocean Research Kiel, Düsternbrooker Weg 20, 24105 Kiel, Germany

2 Max Planck Institute for Meteorology, Hamburg, Germany

3 University of Oslo, 0315 Oslo, Norway

4 Paul Scherrer Institut, 5232 Villigen, Switzerland

5 Desert Research Institute, Reno, NV, USA

6 Centre for Earth Evolution and Dynamics, University of Oslo, PO Box 1028, Blindern, 0315 Oslo, Norway 


\section{Introduction}

In $536 \mathrm{CE}$, observers documented a mysterious cloud which dimmed the light of the sun for at least a year (Stothers and Rampino 1983; Stothers 1984). Tree rings suggest a sudden onset of a decadal-scale exceptional cooling in $536 \mathrm{CE}$ in Northern Europe (Grudd 2008; Larsen et al. 2008; Esper et al. 2012), Mongolia (D'Arrigo et al. 2001), and Western North America (Salzer and Hughes 2007; Salzer et al. 2013), and in the Northern Hemisphere (NH) average (Stoffel et al. 2015). The 536 mystery cloud was linked to crop failures and famines by ancient scholars (Stothers 1999), and has been speculatively linked to a number of major societal crises throughout the $\mathrm{NH}$, including the European outbreak of the plague of Justinian in 541 CE (Baillie 1999; Stothers 1999; Keys 2000).

The documented descriptions of the $536 \mathrm{CE}$ mystery cloud are consistent with the optical characteristics of stratospheric sulfate aerosol resulting from volcanic eruptions (Robock 2000). A volcanic origin of the 536 mystery cloud was only relatively recently confirmed by ice core records. Larsen et al. (2008) reported the presence of two sulfate signals in Greenland ice cores separated by approximately four years around the year $536 \mathrm{CE}$, and linked the second sulfate peak - the signature of a likely tropical eruption - to the 536 mystery cloud. Updated ice core timescales, proposed initially based on matching of ice core and tree ring volcanic signals (Baillie 1994; Baillie 2008; Baillie and McAneney 2015) and recently confirmed through matching of signatures of cosmogenic isotopes in ice cores and tree rings in the 8th century (Sigl et al. 2015), place the two signals at 536 and $540 \mathrm{CE}$. This double peak structure of the ice core records is in qualitative agreement with the temporal character of many tree ring-based temperature reconstructions for this time period (Baillie 1994), with cooling maxima in 536 and again 4 or 5 years later. While more complex eruption sequences are possible, the simplest plausible scenario, assumed hereafter, is one of a volcanic "double event", with two major eruptions from unknown locations in or around the years 536 and $540 \mathrm{CE}$.

While the updated ice core timescales clarify the timing of the 536 and 540 volcanic events, estimates of the magnitudes of climatic impacts stemming from the eruptions differ depending on the source of evidence. Multiple NH tree ring reconstructions suggest that the year 536 was the coldest single year of at least the past 2000 years, and that 536-545 was the coldest decade of the same period (e.g., Larsen et al. 2008; Sigl et al. 2015). However, current estimates from ice cores of the global volcanic radiative forcing over the same interval ranks the 536 and 540 eruptions as only the 18th and 5th strongest events respectively (Sigl et al. 2015). At face value, the magnitudes of the 536 and 540 eruptions derived directly from ice core data appear inconsistent with the exceptional cooling implied by tree ring reconstructions, and therefore do not necessarily support the theory of widespread societal crisis popularly connected to volcanic activity at the time.

To address these apparent inconsistencies in the climatic and societal impacts of the 536 and 540 eruptions implied by different records, we have reconstructed the radiative forcing of the two events with a coupled aerosol-climate model, constrained by ice cores and historical accounts. The reconstructed radiative forcing is then used in 15-year-long simulations with an Earth system model, to estimate global and regional climate anomalies resulting from the 
eruptions. Finally, the climate model results are used to assess the likely societal impacts in Europe of the volcanic double event.

\section{Materials and methods}

\subsection{Volcanic radiative forcing construction}

Available total sulfate flux $\left(\mathrm{kg} / \mathrm{km}^{2}\right)$ derived for the 536 and 540 events from Antarctic and Greenland ice cores (Traufetter et al. 2004; Larsen et al. 2008; Plummer et al. 2012; Sigl et al. 2013) are listed in Table S1. To account for potential sampling bias from the small number of available ice cores available for this time period, and the spatial variability of sulfate deposition to the surface (e.g., Sigl et al. 2014), Antarctic and Greenland averages are corrected using scaling factors derived from MAECHAM5-HAM simulations (Supplementary Methods, (Niemeier et al. 2009; Toohey et al. 2011; Toohey et al. 2013)). The model-based scaling factors for both Greenland and Antarctic based on the four ice core locations in Table S1 are close to unity, with values of 1.01 and 0.93 for Greenland and Antarctica respectively. For the single Antarctic ice core measurement of the 536 event, the scaling factor is 0.73 .

The ratios of Greenland-to-Antarctic sulfate flux for the 536 and 540 events were compared to those of measured historical eruptions (Table S2) and MAECHAM5-HAM simulations (Table S3) to constrain the latitudes of the eruptive sources. Maximum stratospheric sulfate aerosol loading was deduced based on the method of Gao et al. (2007), using scaling factors of $1 * 10^{9} \mathrm{~km}^{2}$ for tropical and $0.57 * 10^{9} \mathrm{~km}^{2}$ for high latitude eruptions. Total $\mathrm{SO}_{2}$ injection by the eruptions is based on scaling the estimated global sulfate aerosol load by the mass ratios of sulfate aerosol to sulfate $\left(\mathrm{M}_{\mathrm{SO} 4} / \mathrm{M}_{\text {Aer }}=0.75\right.$, assuming a $25 \%$ water mass content of the sulfate aerosol) and the molecular weight ratio of $\mathrm{SO}_{2}$ to $\mathrm{SO}_{4}\left(\mathrm{MW}_{\mathrm{SO} 2} / \mathrm{MW}_{\mathrm{SO} 4}=0.66\right)$.

MAECHAM5-HAM simulations were used to construct volcanic aerosol forcing timeseries based on the estimated eruption magnitudes and locations deduced from ice core data. Small ensembles of "candidate" simulations were performed (Table S3) and individual members with closest agreement to ice core-derived hemispheric sulfate deposition were selected and concatenated into a single volcanic radiative forcing timeseries composed of zonal mean aerosol optical depth (AOD) and aerosol effective radius.

\subsection{Climate simulations}

The climate impacts to be expected from the 536 and 540 eruptions were estimated through ensemble simulations with the Max Planck Institute Earth System Model (MPI-ESM, (Giorgetta et al. 2013)) using the reconstructed radiative forcing timeseries as prescribed forcing (as in Timmreck et al. 2010). Initial conditions for 12 ensemble members were defined by the climate state at unique points of time in a 1000-year-long pre-industrial control run performed as part of the 5th phase of the Climate Model Intercomparison project (CMIP5), and were selected so as to span a wide range of climate states in regards to $\mathrm{NH}$ extratropical $\left(30-90^{\circ} \mathrm{N}\right)$ mean temperature (Fig. S2). In addition, care was taken to ensure no bias in the El Niño Southern Oscillation (ENSO) state of the ensemble mean of the initial conditions, with equal numbers of El Niño (Niño $3.4 \approx 1$ ) and La Niña (Niño $3.4 \approx-1$ ) states selected (Fig. S2). 


\section{Results}

\subsection{Radiative forcing}

Categorization of eruptions as tropical or extratropical is necessary to estimate their stratospheric $\mathrm{SO}_{2}$ injection and radiative forcing from ice core sulfate records, and is based on the presence or lack, respectively, of sulfate signals in ice cores from both polar regions. Historical tropical eruptions typically lead to sulfate transport to both hemispheres, and produce Greenland-toAntarctic sulfate flux ratios of between 1:2 and 2:1 (Gao et al. 2007). In contrast, sulfate from extratropical NH eruptions is typically found in Greenland but not Antarctica (Fig. S1). Based on available sulfate flux records (Tables S1, S4), the $540 \mathrm{CE}$ event can be placed in the tropical eruption category, with a 2:1 Greenland-to-Antarctic sulfate flux ratio, similar to that of the eruptions of Huaynaputina $\left(1600,16^{\circ} \mathrm{S}\right)$ and Cosiguina $\left(1835,13^{\circ} \mathrm{N}\right)$. The 536 event has a strong signal in Greenland ice cores, and while a corresponding signal is undetectable in most Antarctic ice cores, a small signal was reported in the high resolution West Antarctic Ice Sheet (WAIS) Divide ice core record (Sigl et al. 2013), suggesting some degree of cross-equator stratospheric transport. The resulting Greenland-to-Antarctic sulfate flux ratio of more than 10:1 can be safely assumed to be representative of a mid or high latitude $\mathrm{NH}$ eruption, which is consistent with detection of tephra in a Greenland ice core consistent in chemical composition to NH volcanoes (Sigl et al. 2015).

Using published volcanic sulfate deposition data (Table S1), and taking the 536 and 540 events as extratropical and tropical eruptions, respectively, and applying established techniques (Gao et al. 2007) for converting sulfate flux to estimates of volcanic stratospheric $\mathrm{SO}_{2}$ injection (Table S4), we estimate global stratospheric $\mathrm{SO}_{2}$ injections of approximately $30 \mathrm{Tg}$ and $50 \mathrm{Tg}$ for the 536 and $540 \mathrm{CE}$ events, respectively. Applying the same procedure and sample of ice cores to estimate the $\mathrm{SO}_{2}$ injection by the 1815 eruption of Tambora results in an estimated $\mathrm{SO}_{2}$ injection of $50 \mathrm{Tg}$, which agrees well with other estimates (Self et al. 1984; Gao et al. 2007).

Simulations with the coupled aerosol-general circulation model MAECHAM5-HAM were performed to construct a timeseries of radiative forcing and aerosol properties. First, a series of sensitivity studies were performed to constrain further eruption parameters such as latitude, season and injection height, in order to produce best agreement between simulations and ice core and historical records of the eruptions.

To select eruption latitudes producing hemispheric aerosol partitioning consistent with the Greenland-to-Antarctic sulfate flux ratios derived from the ice cores, MAECHAM5-HAM simulations were performed of eruptions at a set of latitudes spanning $6^{\circ} \mathrm{S}$ to $56^{\circ} \mathrm{N}$, with eruptions in January and July. Simulated Greenland-to-Antarctic sulfate flux ratios produced largest overlap with the ice core-derived 2:1 deposition ratio of the 540 event for simulated eruptions at $15^{\circ} \mathrm{N}$ (Fig. S1). The roughly 10:1 Greenland-to-Antarctic sulfate flux ratio of the 536 event is similar to MAECHAM5-HAM simulations of mid and high latitude eruptions. MAECHAM5-HAM simulations produce overlap with the observed Greenland-to-Antarctic sulfate deposition ratio for simulated eruptions at both $46^{\circ}$ and $56^{\circ} \mathrm{N}$, and show very little difference in the ensemble mean radiative forcing for eruptions at these two latitudes.

The 536 CE mystery cloud was first observed in late March 536, and persisted for between 12 and 18 months according to observers in Rome and Constantinople (Stothers 1984). Such persistence is surprising compared to recently observed high latitude eruptions, whose radiative effects usually diminish comparatively rapidly (e.g., Bourassa et al. 2010). These recent high latitude eruptions are of relatively small magnitude, and injected sulfur into the lowermost stratosphere, much lower than major eruptions like Pinatubo (1991), which may not be the 
case for larger eruptions like that of $536 \mathrm{CE}$. To test the relationship between decay timescale and injection height, we performed MAECHAM5-HAM simulations of the 536 eruption with injections on March 1 (to allow for a lag between the eruption and first visible effects of the aerosols due to the timescale of $\mathrm{SO}_{2}$ to $\mathrm{SO}_{4}$ conversion) and stratospheric injection heights of 30, 100 and $150 \mathrm{hPa}$ (approximately 24, 16 and $13 \mathrm{~km}$, respectively). Assuming that a dimming of sunlight by more than $10 \%$ would be necessary to be widely perceptible, an injection height of $30 \mathrm{hPa}$ is most consistent with the documented 12-18 month visible persistence of the 536 cloud (Fig. 1). For consistency with modern observations of the height of $\mathrm{SO}_{2}$ injection from the 1991 Pinatubo eruption (Guo 2004), an injection height of $30 \mathrm{hPa}$ is also assumed for the tropical 540 event.

Small ensembles of candidate simulations were then performed for the 536 and 540 events. For 536, an eruption date of March 1 was assumed based on documented first observation of the mystery cloud near the end of March (Stothers 1984). For 540, simulations were performed for January and July eruption dates. Single simulation members which produced best agreement with the ice core-derived hemispheric deposition ratios (Fig. S1) were selected and concatenated to produce a volcanic forcing timeseries covering the 536-550 CE time period (Fig. 2a). The timing of simulated sulfate deposition is in good qualitative agreement with Greenland ice core records under the revised dating, with sulfate flux peaks in 536 and $540 \mathrm{CE}$, and longer duration of sulfate deposition for the second event (Fig. 2b). Simulated Antarctic sulfate deposition (Fig. 2c) shows some qualitative similarities to the ice core record, however there is a discrepancy of about one year in the timing of peak deposition from the 540 eruption. This offset might imply that the tropical eruption occurred in late $539 \mathrm{CE}$ (rather than $540 \mathrm{CE}$ ), however it is also notable that the agreement is significantly improved if the Antarctic ice core record is shifted by +1 year, which can be justified given ice core chronological uncertainty (Sigl et al. 2013).

In terms of global mean, annual mean AOD, the reconstructed 536 and 540 events are comparable to the strongest volcanic eruptions in a reconstruction of volcanic forcing over the past 1200 years (Crowley and Unterman 2013), with magnitudes that would rank 7th and 3rd within this list, respectively. Following the Greenland-to-Antarctica sulfate flux ratios, the simulated AODs for both eruptions are stronger in the NH than in the Southern Hemisphere (SH). The aerosol load for the simulated 536 event is largely constrained to the $\mathrm{NH}$, with the largest AOD

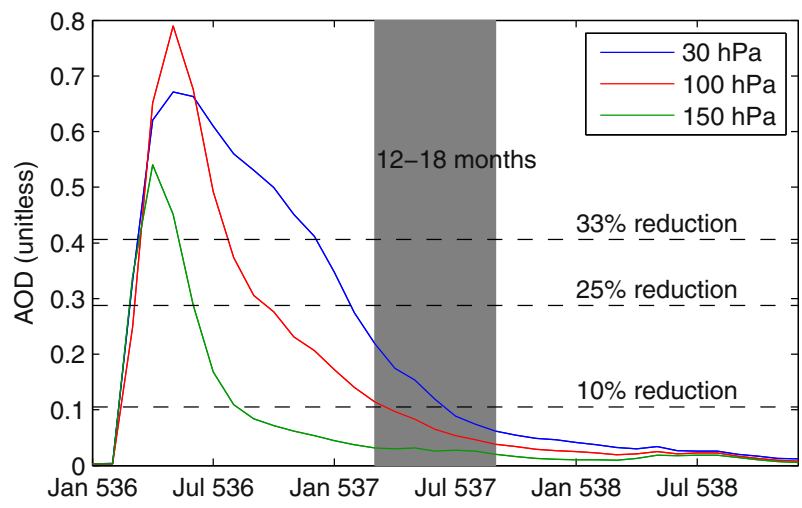

Fig. 1 Simulated visible $(550 \mathrm{~nm})$ aerosol optical depth (AOD) at $42^{\circ} \mathrm{N}$ for extratropical eruptions in March, with stratospheric $\mathrm{SO}_{2}$ injection of $30 \mathrm{Tg}$ and varying injection heights. AOD levels corresponding to $10 \%, 25 \%$ and $33 \%$ reduction in direct solar intensity are marked by dashed lines. Gray shading indicates the period $12-$ 18 months after the simulated eruption, corresponding to the period for which historical records suggest the optical effects of the $536 \mathrm{CE}$ eruption persisted until in Rome $\left(41.9^{\circ} \mathrm{N}\right)$ and Constantinople $\left(41.0^{\circ} \mathrm{N}\right)$ 

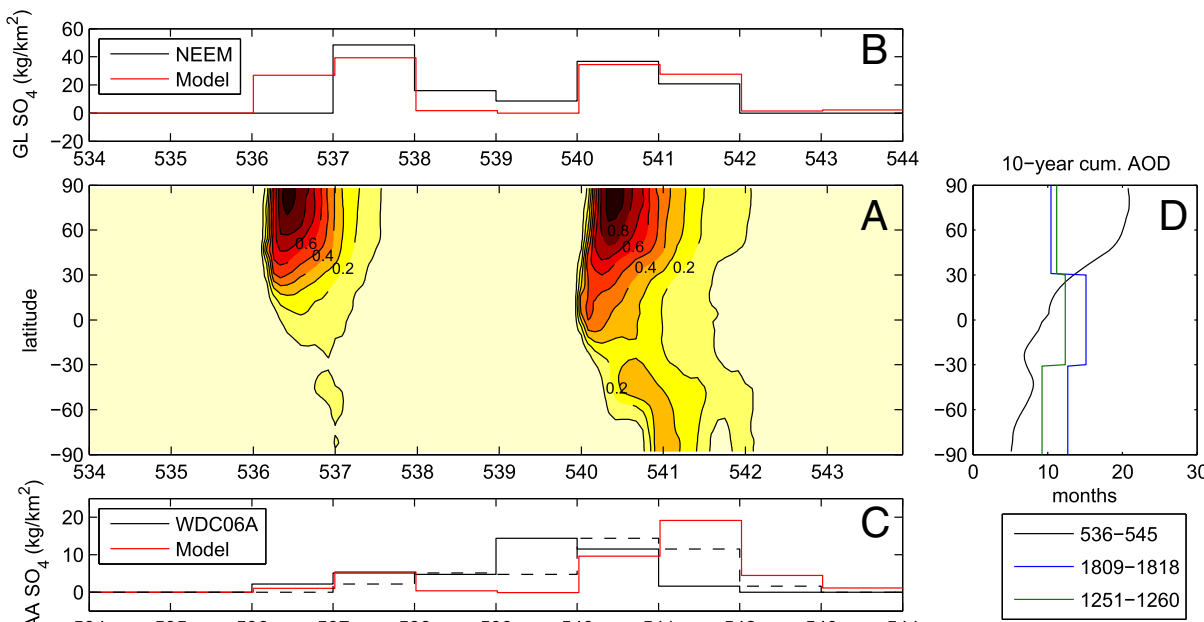

Fig. 2 Volcanic radiative forcing 536-544 CE estimated from ice core records. (a) Reconstructed zonal mean aerosol optical depth at $550 \mathrm{~nm}$ from MAECHAM5-HAM and used as radiative forcing in MPI-ESM simulations. Timeseries of annual volcanic sulfate deposition from the (b) Greenland NEEM(-2011-S1) ice core (Sigl et al. 2013) and (c) Antarctic WDC06A ice core (Sigl et al. 2013) compared to bias-corrected sulfate flux to Greenland and Antarctica in MAECHAM5-HAM simulations. Antarctic ice core flux shifted by +1 year is shown by dashed black line. (d) Decadal cumulative AOD, compared to that of the two largest $\mathrm{NH}$ decadal forcings of the volcanic AOD reconstruction of Crowley and Unterman (2013)

found north of $30^{\circ} \mathrm{N}$, similar to previous model simulations (Oman et al. 2006) and satellite observations (Bourassa et al. 2010) of other high-latitude eruptions. It is also consistent with the distribution of historical observations of diminished solar intensity in $536 \mathrm{CE}$, with the most reliably located accounts originating from Rome $\left(42^{\circ} \mathrm{N}\right)$ and Constantinople $\left(41^{\circ} \mathrm{N}\right)$, but a noted lack of direct observations documented by scholars residing at lower latitudes (Arjava 2005). The structure of the reconstructed forcing for the 540 eruption is qualitatively similar to that of the tropical eruption of Huaynaputina in 1600 (Fig. S2). The exceptional property of the volcanic forcing for the 536/540 double event is therefore not the magnitude or latitudinal structure of either eruption individually, but rather the temporal proximity of two events with strong forcing in the $\mathrm{NH}$ mid and high latitudes. In the decadal cumulative global mean AOD, the 536-545 decade would rank 3rd in the reconstruction of Crowley and Unterman (2013), while in the NH extratropical (30$90^{\circ} \mathrm{N}$ ) mean, the reconstructed 536-545 decadal AOD would rank 1st, with a magnitude approximately 1.5 times larger than the combined impact of the unknown eruption of 1809 and Tambora in 1815 (Fig. 1d), the strongest decadal AOD of the reconstruction of Crowley and Unterman (2013).

\subsection{Climate response}

The constructed radiative forcing timeseries was used as prescribed forcing in twelve 15-year simulations with the MPI-ESM. Initial conditions were taken from a pre-industrial control run, sampled from a wide range of climate conditions (Fig. S3). Simulated NH mean monthly temperature anomalies (Fig. 3) show pronounced decreases following each eruption, with maximum ensemble mean cooling of $-2{ }^{\circ} \mathrm{C}$ reached after the 540 forcing, corresponding to a departure of $8 \sigma$ compared to the variability of the pre-industrial control run. The simulated $\mathrm{NH}$ 536-545 CE decadal temperature anomaly is $-0.7{ }^{\circ} \mathrm{C}$. Temperature anomalies show 


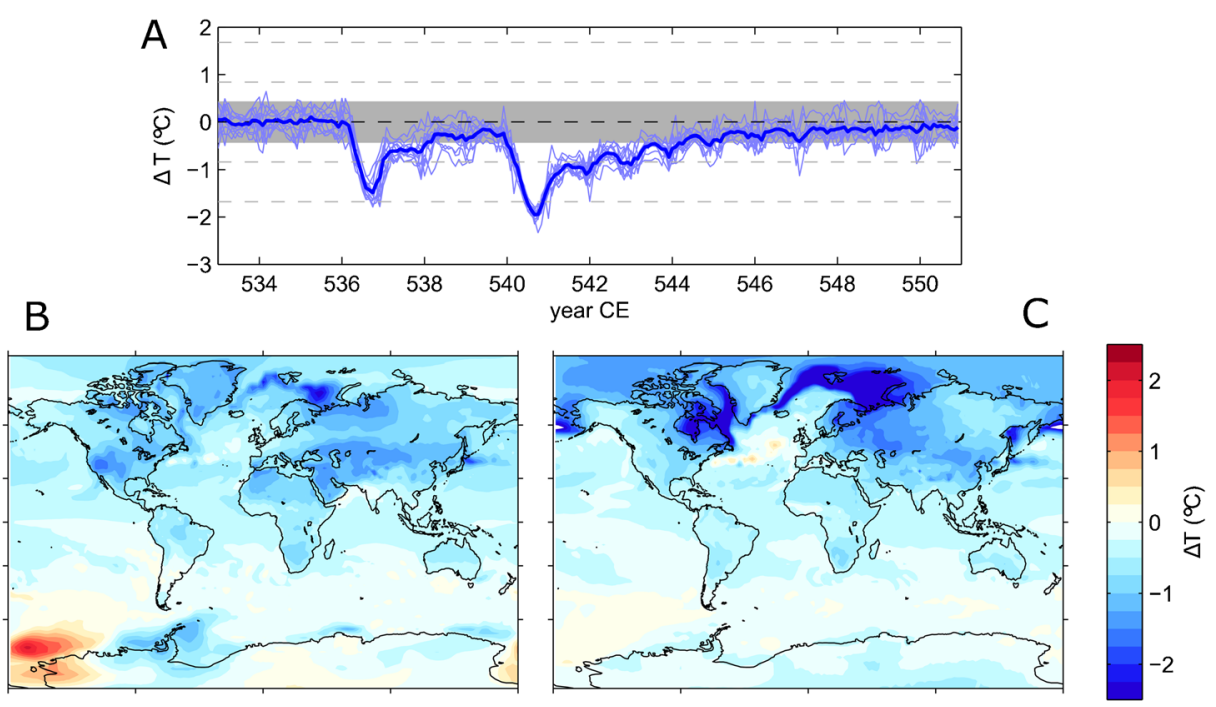

Fig. 3 Surface temperature anomalies simulated by the MPI-ESM in response to the reconstructed volcanic forcing for the 536 and 540 eruptions. (a) Timeseries of simulated Northern Hemisphere mean monthly mean surface temperature anomalies: individual ensemble members shown in light blue, ensemble mean in thick blue. Gray shading shows the $\pm 2 \sigma$ variability of the control run, dashed grey lines show the $\pm 4 \sigma$ and $\pm 8 \sigma$ variability levels. Global maps of the simulated 536-545 CE decadal mean boreal (b) summer and (c) winter mean temperature anomalies

pronounced spatial and seasonal variability (Fig. 3b and c). Simulated summer cooling is greatest predominantly over land masses, with maximum cooling in the midlatitudes (approximately $-1{ }^{\circ} \mathrm{C}$ in decadal mean), and also at high latitudes around the Barents Sea. High latitude cooling, which is also apparent in boreal winter (Fig. 3), and is persistent through the 536-545 CE decade, is related to strong positive sea ice anomalies (Fig. S4), which amplify the impacts of the volcanic radiative cooling, primarily by decreasing sea-to-air heat flux in winter and increasing the surface albedo in summer (Fig. S4).

In many tree ring temperature reconstructions, 536-545 CE includes some of the coldest years of the past 2000 years (Baillie 1994; D’Arrigo et al. 2001; Larsen et al. 2008; Esper et al. 2012). Since records based on tree ring width (RW) can exhibit high year-to-year autocorrelation, maximum latewood density (MXD) is the preferred metric to identify and estimate short-term volcanic cooling (Anchukaitis et al. 2012). The longest MXD records (Grudd 2008; Esper et al. 2012) which cover the relevant time period have been extracted from Northern Fennoscandia (Fig. 4a). The model simulations show good agreement with the two MXD records (Fig. 4b and c), especially in regards to the magnitude of cooling in $536 \mathrm{CE}$. There is considerable ensemble variability in the simulations; for example, the maximum cooling at specific locations occurs in the second summer after the eruption rather than the first in some ensemble members. While the simulations show strong cooling after both the 536 and 540 eruptions, and therefore a significant decadal-scale cooling, they do not reproduce the strong persistence of the cooling after 540 as seen in many RW records (e.g., Larsen et al. 2008). This model-observation mismatch may be related to autocorrelation, caused in part by biological memory effects in RW data extending the apparent signal in time (Anchukaitis et al. 2012), or an under-representation of feedback mechanisms in the climate model that might lead to persistence of the volcanic cooling, especially to this special case of two strong eruptions spaced closely in time. 

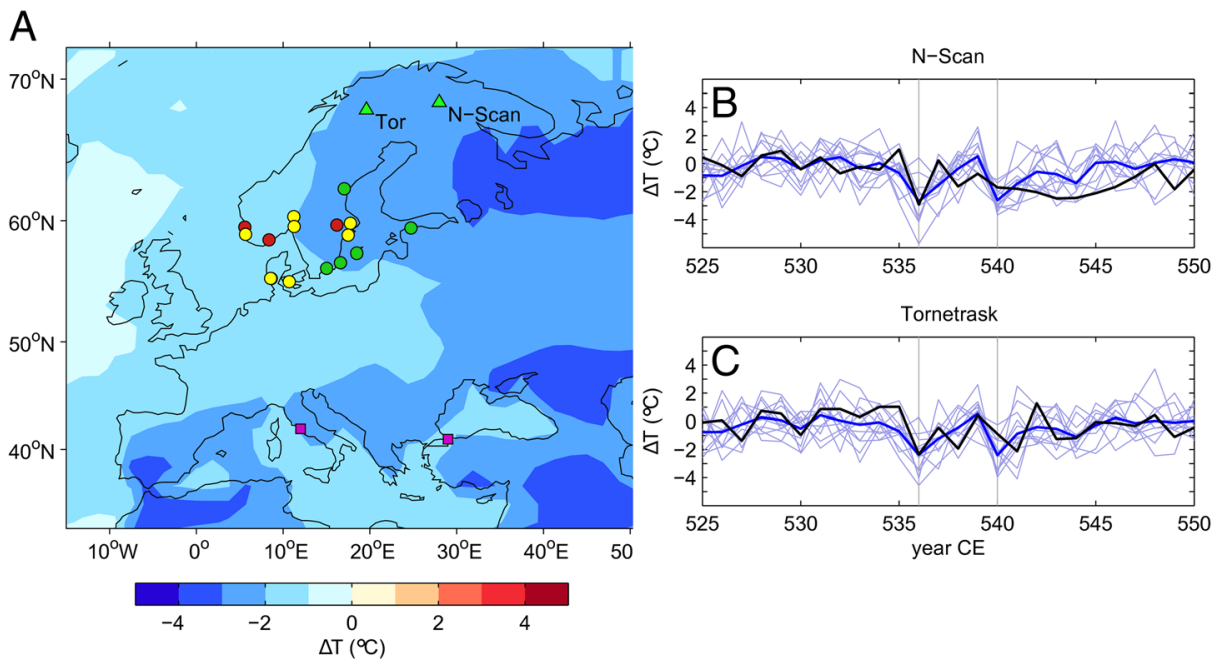

Fig. 4 Simulated and tree ring-based temperature anomalies. (a) Spatial pattern of simulated NH summer (JJA) temperature anomalies for $536 \mathrm{CE}$, shown over the European region. Markers show the locations of the N-Scan (Esper et al. 2012) and Tornetrask (Grudd 2008) maximum latewood density (MXD) temperature reconstructions, and locations of evidence of agricultural changes (green circles) demographic changes (red circles) and sacrificial gold offerings (yellow circles) connected to the $536 \mathrm{CE}$ event (Table S5). Locations of documented observations of the 536 mystery cloud are marked in purple. (b, c) MXD temperature anomalies (black lines) and the simulation results from the corresponding locations. Individual ensemble members shown in light blue, ensemble mean in thick blue

\subsection{Societal impacts}

The 536-545 cold phase has been linked to evidence of societal changes around the globe. Well-dated evidence includes documentation of food shortages or famines in the Mediterranean (Stothers 1984; Rampino et al. 1988; Stothers 1999), Ireland (Baillie 1994), and China (Weisburd 1985), and changes in building frequency in Germany and Ireland (Baillie 1991). Wide ranging societal changes inferred from archaeological and palynological data, and by their nature only roughly constrained to the 6th century, are often speculatively linked to the 536-545 cold phase. For example, the event has been connected to an apparent collapse of Scandinavian societies, evidenced by (Fig. 4a): abandoned settlements (Solberg 2000; Gräslund and Price 2012; Löwenborg 2012), findings of sacrificial gold offerings (Axboe 2001) and evidence of sudden decreases in agriculture (Tvauri 2014; Pedersen and Widgren 2011).

Substantiating links between climatic forcing and societal changes preserved in documentary and archaeological artifacts is inherently complex (Cheyette 2008), but climate model simulations may provide guidance, by allowing the extrapolation of physical evidence to quantitative estimates of the impact on societies. Simulated temperature anomalies are rather uniform across Europe after the 536 (Fig. 4a) and 540 (not shown) eruptions, however, climate variability has a larger impact on society in locations of marginal agriculture, where a given change in temperature represents a larger portion of the annual heat budget (Parry and Carter 1985). This can be illustrated through examining changes in simulated "growing degree days" (GDD), the sum of daily mean temperatures above a given threshold (here, $5^{\circ} \mathrm{C}$ ) throughout the growing season (Bonhomme 2000). In extra-tropical climates where growth is limited by summer warmth rather than water availability, GDD is the primary predictor of crop 

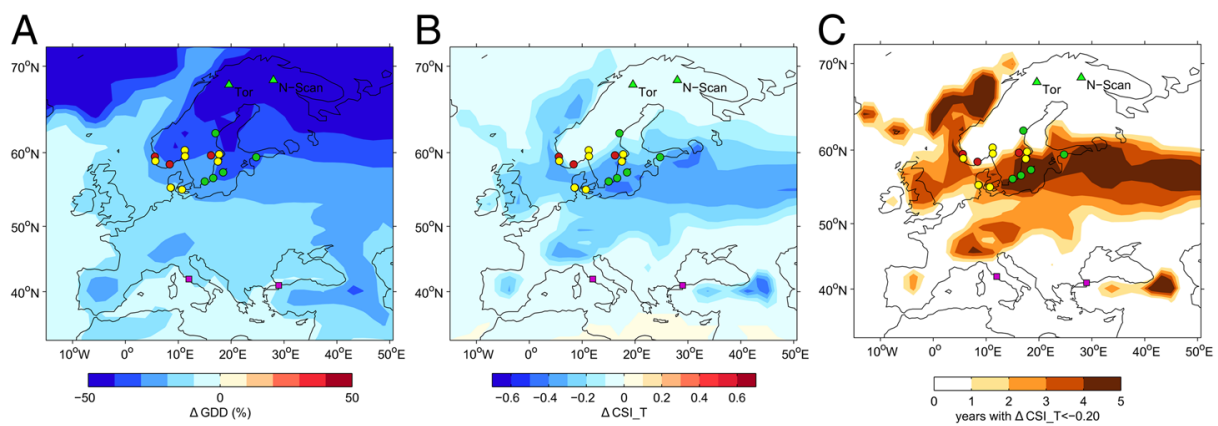

Fig. 5 Impacts of volcanic forcing on accumulated summer warmth and implied agricultural suitability in Northern Europe, 536-545 CE. (a) Simulated GDD percent anomalies in year 536 CE. Symbols show locations of archaeological evidence of societal and agricultural changes dated to the mid-sixth century (Table S5). (b) Anomalies of cultivation suitability index due to changes in temperature $\left(\mathrm{CSI}_{\mathrm{T}}\right.$, see main text) in $536 \mathrm{CE}$. (c) Ensemble mean number of years of the 536-545 decade with $\mathrm{CSI}_{\mathrm{T}}$ anomalies exceeding -0.2

development. Simulated percent GDD anomalies in $536 \mathrm{CE}$ over Europe (Fig. 5a), are approximately $10 \%$ in most of central and southern Europe, and increase strongly with latitude, reaching values of $20-30 \%$ in Northern Europe around the Baltic Sea. At the latitudes of the MXD tree ring reconstructions, the simulated temperature anomalies represent GDD decreases of more than $50 \%$.

A picture of the absolute changes in agricultural productivity resulting from volcanic cooling can be constructed with the help of an index of temperature dependent cultivation suitability $\left(\mathrm{CSI}_{\mathrm{T}}\right)$, based on the observed relationship between modern cultivation and GDD (Ramankutty et al. 2002), and expressed as

$$
C S I_{T}=\frac{1}{1+\exp (0.0052(1334-G D D))} .
$$

Using this metric, the simulated temperature anomalies for $536 \mathrm{CE}$ imply greatest absolute agricultural impact in Europe in high altitude regions (e.g., over the Alps) and at the northernmost margin of nominal cultivation (Fig. 5b). The decrease in the $\mathrm{CSI}_{\mathrm{T}}$ is especially pronounced in the Baltic sea region, with absolute decreases of $0.3-0.4$. In many Scandinavian locations, these decreases amount to a complete diminishment of $\mathrm{CSI}_{\mathrm{T}}$, implying severe crop failure. Decreases in simulated $\mathrm{CSI}_{\mathrm{T}}$ after the 540 eruption (not shown) is roughly similar to that of 536, and due to the temporal proximity of the two strong volcanic events, and the persistence of each event through two summers, such crop failure is likely to have occurred for multiple years within 536-545: in the ensemble average, $\mathrm{CSI}_{\mathrm{T}}$ anomalies exceed -0.2 for $3-5$ years in the Baltic sea region during the 536-545 period (Fig. 5c).

\section{Discussion and conclusions}

Ice core data combined with historical evidence indicates that the mid-6th century was marked by multiple major volcanic eruptions. Using eruption parameters constrained by ice core and documentary evidence, and the MAECHAM5-HAM aerosol-climate model, we have reconstructed the volcanic radiative forcing for a plausible scenario of major eruptions in 536 and 
$540 \mathrm{CE}$. Consistency between the ice core records, MXD tree ring temperature reconstructions, and historical observations of the 536 event can be achieved under the scenario of a high latitude $\mathrm{NH}$ eruption producing a high altitude sulfur injection, consistent with contemporary observations of major tropical eruptions, but as yet not observed for extratropical eruptions. This result suggests that the climate impact of extratropical eruptions may not always be as minor compared to tropical eruptions as deduced from prior studies (e.g., Schneider et al. 2009). Best agreement with ice core records of the ca. $540 \mathrm{CE}$ eruption was achieved from simulation of a eruption at $15^{\circ} \mathrm{N}$, consistent with the location of Ilopango, one suggested source of a major eruption at this time (Dull et al. 2010). Based on the ice core data, our simulations suggest very strong radiative forcing in the $\mathrm{NH}$ high latitudes resulting from both eruptions, such that the decadal average radiative forcing in the NH extratropics is $50 \%$ larger than the largest such forcing of the past 1200 years. These conclusions are to some degree dependent on the assumption of two single eruptions: if the 536 sulfate peak was due to multiple $\mathrm{NH}$ eruptions (a possibility suggested by tephra analysis of a Greenland ice core (Sigl et al. 2015)), the resulting radiative forcing could potentially be weaker than that estimated here. Constraining the eruption sequence at this time, and generally the uncertainties related to estimating sulfur injection and radiative forcing from ice core sulfate signals, are topics in need of further study.

Earth system model simulations using the reconstructed forcing show good agreement with tree ring reconstructions from Northern Scandinavia, especially in regards to the cooling after the $536 \mathrm{CE}$ event. While persistent decadal-scale cooling after $540 \mathrm{CE}$ - apparent in some tree ring width records (e.g., D'Arrigo et al. 2001; Larsen et al. 2008) - is not reproduced by the model at the locations of the Scandinavian tree ring samples, decadal-scale anomalies of Arctic sea ice are produced, suggesting a possible mechanism for longer term climate response. If sea ice growth is an important mechanism in the prolongation of short-term volcanic radiative forcing into decadal scale climate responses (e.g., Schneider et al. 2009; Schleussner and Feulner 2013; Lehner et al. 2013), it may be that the characteristics of the 536/540 double event, which produced strong radiative forcing at $\mathrm{NH}$ high latitudes focused over a single decade, may have been especially effective at creating climate anomalies persisting well after the eruptions.

Finally, the simulated temperature anomalies are interpreted in terms of impact on agriculture, quantified through changes in growing degree days (GDD) and an index of cultivation suitability. We find that while temperature anomalies were likely similar across most of Europe, the direct impact of the eruptions on agricultural production in southern regions was likely minimal, consistent with documentary evidence from the time (Arjava 2005). In contrast, the simulations imply that marginal agricultural societies of Northern Europe most likely faced multiple years of crop failure within a single decade as a result of the two eruptions. It is clear that the widespread societal changes in the 6th century which mark the end of Antiquity and the beginning of the Middle Ages, deduced from documentary and archaeological evidence, are due to a complex set of causes, many of which unrelated to (or potentially indirect impacts of) volcanic activity. However, the modeling results shown here, incorporating estimates of volcanic radiative forcing derived directly from ice core records, support the theory of a direct role of the 536 and 540 eruptions on agricultural and societal changes in Northern Europe and Scandinavia.

Acknowledgments This work was supported by the Research Council of Norway through its Centres of Excellence funding scheme to Centre of Earth Evolution and Dynamics (CEED) project number 223272, and by the Federal Ministry for Education and Research in Germany (BMBF) through the research program 'MiKlip' (FKZ:01LP130B). Computations were performed at the German Climate Computer Center (DKRZ). The authors thank Jan. Esper for providing the N-Scan data set, and two anonymous reviewers for their insightful comments. 
Open Access This article is distributed under the terms of the Creative Commons Attribution 4.0 International License (http://creativecommons.org/licenses/by/4.0/), which permits unrestricted use, distribution, and reproduction in any medium, provided you give appropriate credit to the original author(s) and the source, provide a link to the Creative Commons license, and indicate if changes were made.

\section{References}

Anchukaitis KJ, Breitenmoser P, Briffa KR, et al. (2012) Tree rings and volcanic cooling. Nat Geosci 5:836-837. doi:10.1038/ngeo1645

Arjava A (2005) The mystery cloud of 536 CE in the Mediterranean sources. Dumbart Oaks Pap 59:73-94

Axboe M (2001) Amulet pendants and a darkened sun. In: Magnus B (ed) Roman gold and the development of the early Germanic kingdoms, history and antiquities. Royal Academy of Letters, Stockholm, pp 119-136

Baillie MGL (1991) Marking in marker dates: towards an archaeology with historical precision. World Archaeol 23:233-243. doi:10.1080/00438243.1991.9980175

Baillie MGL (1994) Dendrochronology raises questions about the nature of the AD 536 dust-veil event. The Holocene 4:212-217. doi:10.1177/095968369400400211

Baillie MGL (1999) Exodus to Arthur: catastrophic encounters with comets. BT Batsford Ltd, London

Baillie MGL (2008) Proposed re-dating of the European ice core chronology by seven years prior to the 7th century AD. Geophys Res Lett 35:L15813. doi:10.1029/2008GL034755

Baillie MGL, McAneney J (2015) Tree ring effects and ice core acidities clarify the volcanic record of the first millennium. Clim Past 11:105-114. doi:10.5194/cp-11-105-2015

Bonhomme R (2000) Bases and limits to using “degree.day” units. Eur J Agron 13:1-10. doi:10.1016/S11610301(00)00058-7

Bourassa AE, Degenstein DA, Elash BJ, Llewellyn EJ (2010) Evolution of the stratospheric aerosol enhancement following the eruptions of Okmok and Kasatochi: Odin-OSIRIS measurements. J Geophys Res. doi:10. 1029/2009JD013274

Cheyette FL (2008) The disappearance of the ancient landscape and the climatic anomaly of the early Middle Ages: a question to be pursued. Early Mediev Eur 16:127-165. doi:10.1111/j.1468-0254.2008.00225.x

Crowley TJ, Unterman MB (2013) Technical details concerning development of a 1200 yr proxy index for global volcanism. Earth Syst Sci Data 5:187-197. doi:10.5194/essd-5-187-2013

D’Arrigo R, Frank D, Jacoby G, Pederson N (2001) Spatial response to Major Volcanic events in or about AD 536, 934 and 1258: frost rings and other dendrochronological evidence from Mongolia and Northern Siberia: comment on R. B. Stothers, 'Volcanic dry fogs, climate cooling, and plague pandemics in Europe and the Middle East'. Clim. Change 49:239-246. doi:10.1023/A:1010727122905

Dull R, Southon JR, Kutterolf S, et al (2010) Did the TBJ Ilopango eruption cause the AD 536 event? AGU Fall Meet Abstr $-1: 2370$.

Esper J, Büntgen U, Timonen M, Frank DC (2012) Variability and extremes of Northern Scandinavian summer temperatures over the past two millennia. Glob Planet Change 88-89:1-9. doi:10.1016/j.gloplacha.2012.01.006

Gao C, Oman L, Robock A, Stenchikov GL (2007) Atmospheric volcanic loading derived from bipolar ice cores: accounting for the spatial distribution of volcanic deposition. J Geophys Res. doi:10.1029/2006JD007461

Giorgetta MA, Jungclaus J, Reick CH, et al. (2013) Climate and carbon cycle changes from 1850 to 2100 in MPI-ESM simulations for the Coupled Model Intercomparison Project phase 5. J Adv Model Earth Syst 5: 572-597. doi:10.1002/jame.20038

Gräslund B, Price N (2012) Twilight of the gods? the "dust veil event" of AD 536 in critical perspective. Antiquity 86:428-443. doi:10.1017/S0003598X00062852

Grudd H (2008) Torneträsk tree-ring width and density AD 500-2004: a test of climatic sensitivity and a new 1500year reconstruction of north Fennoscandian summers. Clim Dyn 31:843-857. doi:10.1007/s00382-007-0358-2

Guo S (2004) Re-evaluation of SO 2 release of the 15 June 1991 Pinatubo eruption using ultraviolet and infrared satellite sensors. Geochemistry Geophys Geosystems. doi:10.1029/2003GC000654

Keys D (2000) Catastrophe: An investigation into the origins of the modern world. Ballantine, New York

Larsen LB, Vinther BM, Briffa KR, et al. (2008) New ice core evidence for a volcanic cause of the A.D. 536 dust veil. Geophys Res Lett. doi:10.1029/2007GL032450

Lehner F, Born A, Raible CC, Stocker TF (2013) Amplified inception of European little ice age by sea IceOcean-atmosphere feedbacks. J Clim 26:7586-7602. doi:10.1175/JCLI-D-12-00690.1

Löwenborg D (2012) An Iron Age shock doctrine: did the AD 536-7 event trigger large-scale social changes in the Mälaren valley area? J Archaeol Anc Hist 4:1-29

Niemeier U, Timmreck C, Graf H-F, et al. (2009) Initial fate of fine ash and sulfur from large volcanic eruptions. Atmos Chem Phys 9:9043-9057. doi:10.5194/acp-9-9043-2009 
Oman L, Robock A, Stenchikov GL, et al. (2006) Modeling the distribution of the volcanic aerosol cloud from the 1783-1784 Laki eruption. J Geophys Res. doi:10.1029/2005JD006899

Parry ML, Carter TR (1985) The effect of climatic variations on agricultural risk. Clim Chang 7:95-110. doi:10. 1007/BF00139443

Pedersen EA, Widgren M (2011) Agriculture in Sweden 800 BC-AD 1000. In: Myrdal J, Morell M (eds) The Agrarian History of Sweden: From 4000 BC to AD 2000. Academic Press, Nordic, pp. 46-71

Plummer CT, Curran MAJ, van Ommen TD, et al. (2012) An independently dated 2000-yr volcanic record from Law Dome, East Antarctica, including a new perspective on the dating of the 1450s CE eruption of Kuwae, Vanuatu. Clim Past 8:1929-1940. doi:10.5194/cp-8-1929-2012

Ramankutty N, Foley JA, Norman J, McSweeney K (2002) The global distribution of cultivable lands: current patterns and sensitivity to possible climate change. Glob Ecol Biogeogr 11:377-392. doi:10.1046/j.1466822x.2002.00294.x

Rampino MR, Self S, Stothers RB (1988) Volcanic winters. Annu Rev Earth Planet Sci 16:73-99. doi:10.1146/ annurev.ea.16.050188.000445

Robock A (2000) Volcanic eruptions and climate. Rev Geophys 38:191-219. doi:10.1029/1998RG000054

Salzer MW, Hughes MK (2007) Bristlecone pine tree rings and volcanic eruptions over the last 5000 yr. Quat Res 67:57-68. doi:10.1016/j.yqres.2006.07.004

Salzer MW, Bunn AG, Graham NE, Hughes MK (2013) Five millennia of paleotemperature from tree-rings in the Great Basin, USA. Clim Dyn 42:1517-1526. doi:10.1007/s00382-013-1911-9

Schleussner CF, Feulner G (2013) A volcanically triggered regime shift in the subpolar North Atlantic Ocean as a possible origin of the Little Ice Age. Clim Past 9:1321-1330. doi:10.5194/cp-9-1321-2013

Schneider DP, Ammann CM, Otto-Bliesner BL, Kaufman DS (2009) Climate response to large, high-latitude and low-latitude volcanic eruptions in the Community Climate System Model. J Geophys Res 114:D15101. doi: 10.1029/2008JD011222

Self S, Rampino MR, Newton MS, Wolff JA (1984) Volcanological study of the great Tambora eruption of 1815. Geology 12:659-663. doi:10.1130/0091-7613(1984)12\%3C659:VSOTGT\%3E2.0.CO;2

Sigl M, McConnell JR, Layman L, et al. (2013) A new bipolar ice core record of volcanism from WAIS divide and NEEM and implications for climate forcing of the last 2000 years. J Geophys Res Atmos 118:11511169. doi:10.1029/2012JD018603

Sigl M, McConnell JR, Toohey M, et al. (2014) Insights from Antarctica on volcanic forcing during the Common Era. Nat Clim Chang 4:693-697. doi:10.1038/nclimate2293

Sigl M, Winstrup M, McConnell JR, et al. (2015) Timing and climate forcing of volcanic eruptions for the past 2,500 years. Nature 523:543-549. doi:10.1038/nature14565

Solberg B (2000) Jernalderen i Norge: ca. 500 f. Kr.-1030 e. Kr. Oslo: Cappelen Akademisk Forlag

Stoffel M, Khodri M, Corona C, et al. (2015) Estimates of volcanic-induced cooling in the Northern Hemisphere over the past 1,500 years Nat Geosci. doi:10.1038/ngeo2526

Stothers RB (1984) Mystery cloud of AD 536. Nature 307:344-345. doi:10.1038/307344a0

Stothers RB (1999) Volcanic dry fogs, climate Cooling, and plague pandemics in Europe and the Middle East. Clim Chang 42:713-723. doi:10.1023/A:1005480105370

Stothers RB, Rampino MR (1983) Volcanic eruptions in the Mediterranean before A.D. 630 from written and archaeological sources. J Geophys Res 88:6357. doi:10.1029/JB088iB08p06357

Timmreck C, Graf H-F, Lorenz SJ, et al. (2010) Aerosol size confines climate response to volcanic supereruptions. Geophys Res Lett 37:L24705. doi:10.1029/2010GL045464

Toohey M, Krüger K, Niemeier U, Timmreck C (2011) The influence of eruption season on the global aerosol evolution and radiative impact of tropical volcanic eruptions. Atmos Chem Phys 11:12351-12367. doi:10. 5194/acp-11-12351-2011

Toohey M, Krüger K, Timmreck C (2013) Volcanic sulfate deposition to Greenland and Antarctica: A modeling sensitivity study. J Geophys Res Atmos 118:4788-4800. doi:10.1002/jgrd.50428

Traufetter F, Oerter H, Fischer H, et al (2004) Spatio-temporal variability in volcanic sulphate deposition over the past $2 \mathrm{kyr}$ in snow pits and firn cores from Amundsenisen, Antarctica. J Glaciol 50(168):137-146. doi:10. $3189 / 172756504781830222$

Tvauri A (2014) The impact of the climate catastrophe of 536-537 AD in Estonia and neighbouring areas. Est J Archaeol 18:30-56

Weisburd S (1985) Excavating words: a geological tool. Sci News 127:91-94 